\title{
Development of a photonics outreach and education program through partnerships at Universidad Metropolitana for Puerto Rico and the IYL
}

A. Diaz, J. Friedman, R. Saltares, R. Gordillo, E. Trujillo

A. Diaz, J. S. Friedman, R. Saltares, R. Gordillo, E. Trujillo, "Development of a photonics outreach and education program through partnerships at Universidad Metropolitana for Puerto Rico and the IYL," Proc. SPIE 9946, Optics Education and Outreach IV, 994606 (27 September 2016); doi: $10.1117 / 12.2238039$

SPIE Event: SPIE Optical Engineering + Applications, 2016, San Diego, California, United States 


\title{
Development of a photonics outreach and education program through partnerships at Universidad Metropolitana for Puerto Rico and the IYL
}

\author{
A. Diaz ${ }^{1}$, J. S. Friedman, R. Saltares, R. Gordillo, and E. Trujillo \\ Puerto Rico Photonics Institute, School of Environmental Affairs, Universidad Metropolitana, 1399 \\ Ave. Ana G Mendez Ave., San Juan, PR 00926-2602
}

\begin{abstract}
As the only photonics center in Puerto Rico and the Caribbean we have developed since 2014 and for the International Year of Light 2015 a comprehensive education and outreach program. We show how we have successfully reached an audience of more than 9,500 including K-12 students and teachers, general public, and specialized audiences, by partnering with other institutions and private companies to maximize resources. We present our experience, challenges, rewards and results or our activities and the types of partnerships we developed with institutions and private companies that were fundamental to achieve our goals.
\end{abstract}

Keywords: Photonics Education, Outreach, K-12, Continuing Education, International Year or Light, STEAM Outreach, Puerto Rico

\section{INTRODUCTION}

The Puerto Rico Photonics Institute (PRPI), part of the School of Environmental Affairs at Universidad Metropolitana (UMET) in San Juan, Puerto Rico, is the first and only institute of its kind dedicated to doing teaching, research, workforce development, and outreach in the areas of Lasers, Optics, and Photonics in Puerto Rico. PRPI was established in 2012 and beginning in 2014 we developed a comprehensive outreach program thanks to the foundational support received from the Puerto Rico Industry Development Company (PRIDCO), the Puerto Rico Science, Technology and Research Trust (PRSTRT), and the association with intiatives such as the U.S. Department of Education's Mathematics and Science Partnerships (MSP) program. Activities organized included conferences at different institutions, workshops for teachers, mini-workshops for K-12 students at summer camps and schools, visits of schools to the PRPI labs, continuing education programs for engineers and engineering students, development of two videos, radio and TV interviews, participation at STEM events, and exhibitions at libraries, universities, malls, and other venues. The primary goal of these events was to create awareness of the importance and impact that photonics and light-based technologies have on everyday life to encourage and motivate more Puerto Ricans to enter, study and succeed in these STEM fields.

In 2014 we also started developing our academic program, initially offering undergraduate and continuing education courses, and have partnered with the National Center for Optics and Photonics Education (OP-TEC), the University of Arizona College of Optics, and the College of Optics \& Photonics at the University of Central Florida (CREOL) to further our educational offering through curriculum development and STEM education proposals and initiatives. On September 29, 2014, PRPI was announced as recipient of a US Department of Labor Trade Adjustment Assistance Community College and Career Training Grant through our New Horizons: Puerto Rico Lasers and Photonics Career Pathways initiative ${ }^{2}$. As part of the academic component of this grant, a one-year Certificate in Photonics \& Lasers Technical Specialist program was developed and approved by the Puerto Rico Council of Education in June 19, 2015. The curriculum for this program is adapted from OP-TEC with a remote online interactive component being developed in collaboration with the University of Arizona. The first cohort of students started in March 2016. Close collaboration

\footnotetext{
${ }^{1}$ adiazg@suagm.edu; phone 1787 766-1717 x 6618; http://prpi.suagm.edu

${ }^{2}$ US Department of Labor under the Trade Adjustment Assistance Community College and Career Training program. Grant \# TC-26472-14-60-A-72
}

Optics Education and Outreach IV, edited by G. Groot Gregory, Proc. of SPIE Vol. 9946, 994606

(C) 2016 SPIE · CCC code: $0277-786 \mathrm{X} / 16 / \$ 18 \cdot$ doi: $10.1117 / 12.2238039$ 
with local industry is also included as part of an internship program and through the development of our current Industry Affiliates Program.

We are also actively building our research program, with support provided by our foundational sponsors, and with additional grants from the MIT Draper Lab (laser gyro device development for a turbulence sensor), University of Colorado-Boulder (research collaboration), and the Puerto Rico Science Trust (Inertial Sensors Development for Space Weather and Planetary Research).

Of special significance has been the relationship between Universidad Metropolitana and the Arecibo Observatory (AO). Currently, the AO is managed by a partnership between the Space Research Institute (SRI International), UMET, and the Universities Space Research Association (USRA). Our director, J.S. Friedman, is a research professor employed by UMET and a Senior Research Associate at AO employed by SRI. This dual role has helped PRPI work very closely with the AO in research, outreach and educational programs, in a relationship that benefits both UMET and the Observatory.

In December 2013, the United Nations General Assembly voted to declare the year 2015 as the International Year of Light and Light-Based Technologies (IYL2015). This declaration recognizes the vital importance of lasers, fiber optics, and related technologies in modern technologies that we have come to accept as part of our lives. Drs. Andres Diaz and Jonathan Friedman were designated as the official contacts for Puerto Rico and responsible for posting Puerto Rico activities in the IYL2015 calendar.

At the state level, the Puerto Rico House of Representatives declared 2015 the International Year of Light and LightBased Technologies (Proyecto de la Cámara $\# 2267^{3}$ on 1 June 2015). In support of that law, the Puerto Rico Science, Research and Technology Trust sent a letter to Governor Alejandro Garcia Padilla on May 28, 2015 affirming its commitment as foundational supporter of PRPI and expressing it would work with us on dissemination activities related to the themes of light and related technologies. As a result, the Puerto Rico Photonics Institute hosted a three-day event in Puerto Rico that included continuing education and scientific conferences directed at the science, technology, engineering and mathematics (STEM) community, an open house of the first dedicated photonics laboratory in Puerto Rico, presentation of the first Technical Certificate in Photonics and Lasers, and an innovative outreach event that presented the science of light and the fruits of light-based technology merged with music performed by the Puerto Rico Symphony Orchestra.

In this paper we will describe: partnerships that have allowed us to reach, with a small group of collaborators, more than 9,000 people of over $95 \%$ of the counties in Puerto Rico; types of activities we have organized and participated in; the three-day event we hosted in celebration of IYL 2015; and the significance of these activities in the context of the current social and economic situation of Puerto Rico.

\section{PARTNERSHIPS DEVELOPED}

Our outreach effort would not have been possible without the active help of many state and federal organizations and institutions. We hope this information may be useful to other colleges and universities. In order to better present the information, we have organized them in the categories below.

\subsection{Foundational support and grants}

From its establishment in 2012, PRPI has counted with the active support of the Ana G. Mendez System University System, the UMET University Chancellor, and the Dean of Environmental Affairs. This active support has been fundamental in the growth of the institute and in obtaining the support of Puerto Rican institutions. As previously mentioned, PRIDCO and the PR Science Trust provided foundational support for the PR Photonics Institute. PRIDCO provided the funds (matched by UMET) for the personnel (two faculty and one technician) responsible for research, teaching, curriculum development, and the general operation of the institute. PRIDCO funds have also paid for stipends for students who have been instrumental in developing our outreach program. The PR Science Trust provided for laboratory infrastructure (laboratory equipment) for our academic and research programs. This equipment has also been used to showcase PRPI's capabilities for schools visiting our facilities.

${ }^{3}$ http://www.tucamarapr.org/dnncamara/Documents/Measures/74c7b55f-3d6f-438f-b6c4-12bdb6db4a3b.pdf 
In 2014, PRPI was the recipient of an Education Outreach Grant from the International Society for Optics and Photonics (SPIE). This grant allowed us to buy equipment and supplies PRPI has used to setup demonstrations in optics and photonics for our outreach program. These include the development of a laser fountain (coupling of a laser to a stream of water to show the principles of total internal reflection and fiber optics), a balloon popping setup (used to teach about the nature of color and energy in light), the development of a laser pattern generator (Capstone Project with senior electrical and mechanical engineering students from Universidad del Turabo, our sister institution), a laser set and green laser OEM module (for the balloon popping setup and for general light demos) and other consumables. These demonstrations have been used with different populations and have been a building block for our outreach program.

In both 2014 and 2015 PRPI was also the recipient of OP-TEC Student Recruitment grants. These grants have allowed us to hire as half-time recruiter Mr. Rubén A. Gordillo, MBA, adjunct professor from the School of Business. He has been instrumental in developing and implementing a marketing plan and outreach program. We have been able to leverage this grant by having, at different times, an intern from the School of Business' Marketing Program (supervised by Prof. Gordillo), an intern from the Juvempleo program (see below), and a student paid by our PRIDCO grant. These students received training in the principles of optics and photonics and in each of the demos we wanted to show, and they gave us feedback on how to better present this information to our different audiences. Additionally, the 2014 SPIE grant allowed us to acquire additional material we needed for our outreach and recruitment efforts.

\subsection{Local and national professional societies}

We have also reached to the Optical Society of America (OSA) for help in our outreach and educational program. OSA donated in 2014 a demo optics kit that we have been actively using since then. In 2015 we additional bought two more optics kits from them. In addition to the SPIE Education Outreach Grant, we have also received 100 copies of each of four posters prepared by them for IYL: "IYL: What is light?", "Light as a wave", "Light as a particle", and "Light as a ray". We have given away these posters to teachers and parents at some of our activities, and will continue to do so. We also have SPIE and OSA posters prominently displayed in our labs.

In 2015 we also partnered with the Puerto Rico Manufacturer's Association and gave a 3-hour workshop for college students (in San Juan) and 1.5 hour workshops for junior and senior students at vocational high schools (held in C3Tec museum in Caguas).

\subsection{State and non-profit organizations}

In addition to PRIDCO, the PR Science Trust, and the PR House of representatives, we partnered with several organizations in order to expand the reach of our programs. These were:

- The State Department of Education, who invited us to participate in the VII Congress of Math and Science Teachers. This contact was done through UMET's MSP program office, that at the time was led by Ms. Elsa Trujillo who has now joined our group as director of the DoL New Horizon project. Through this partnership we were able to give a 3-hour workshop to Science teachers from across PR, and another 3-hour workshop to both Math and Science teachers as plenary speakers at the event.

- The Puerto Rico Office of Youth Affairs (dependency of the Governor's office), through the Juvempleo program agreement with UMET. Through Juvempleo we had in 2015 a senior student from the School of Business' BS Marketing Program working 20 hours a week for 6 months helping us with our outreach and recruiting activities.

- Musical Arts Corporation, public corporation of the Commonwealth of Puerto Rico and parent company of the Puerto Rico Symphony Orchestra Corporation. Our partnership with them allowed us to present the Concert of Light with the PR Symphony Orchestra, one of the four events of our IYL week in PR.

- KV265, a non-profit organization, whose mission is the communication of science through art. Dr. José Francisco Salgado, executive director of KV265, integrated his science photography and commentary to the pieces performed by the PR Symphony Orchestra for a magical sensorial experience at our Concert of Light.

- Northern Technological Initiative (INTENOR), multisector alliance created in the northern-central region of PR to promote activities of economic, industrial, technological, and academic development. The affiliation of INTENOR with UMET was instrumental in having our laboratories located at INTENOR's Business Incubator. 
This incubator was established through an Economic Development Administration (EDA) project of the US Department of Commerce ${ }^{4}$. We actively participate in programs developed by INTENOR, including a "INTENOR's Scientific Park Visit" program which brought during 2014 and 2015 almost 2,500 K-12 students from 32 public and private schools for 30 -minute visits to our labs.

- Caribbean Center for Science and Technology (C3Tec), non-profit museum in Caguas where we held 1.5-hour workshops for 390 vocational high-school students (divided into three groups), in partnership with Puerto Rico Manufacturer's Association.

- Puerto Rico Museum of Art: we partnered with the educational office of the PRMoA to participate in their "Careers Day" where we had a short presentation on what is photonics and what is its use in the arts. We also started developing with them a laser pattern generator display for their interactive gallery as part of IYL 2015 (activARTE). Resource constraints from both sides prevented us from developing the idea further.

- Puerto Rico Wildlife Museum: the museum director has been very receptive to any idea where we can involve K-12 teachers and students. To date we have not worked with them directly.

- SRI and the Arecibo Observatory: as mentioned above, the close relationship between UMET and the Arecibo Observatory has resulted in collaboration with their Science \& Visitors Center in several activities. These include Yuri's Night (During the Day) and Space Week Closing.

\subsection{Educational institutions}

Cooperation between UMET and other institutions has also helped us spread the word about our work and our programs. We have collaborated with:

- University del Turabo, sister institution that falls under the Ana G. Mendez University System (AGMUS) of which UMET is also part of. We have worked with their School of Engineering, and had two students from their Electrical and Mechanical programs work with PRPI in their Capstone course. They design the Laser Pattern Generator Display which we showed in several teacher workshops. We also worked with Turabo's PREC (Puerto Rico Energy Center) offering a Continuing Education Course on Laser Systems and Applications as part of their VII International Symposium in Applied Science and Engineering in February 2015.

- Sistema TV: part of AGMUS, Sistema TV is the first and only educational TV and PBS station in Puerto Rico. Sistema TV presented information on PRPI and our outreach activities in the context of the IYL, and has also created a 30 second promo for our 1-year Certificate Program.

\subsection{Private companies}

We are thankful for the different kinds of support private companies have given PRPI. In particular:

- Honeywell: provided a scholarship so five of the students that started working with us could officially register a course in Modern Optics given by our faculty. These students not only learned about optics, but went on to contribute with our research and outreach programs.

- Edmund Optics: provided a donation of polarization sheets that we initially needed for our workshops at the VII Congress of Math and Science Teachers. We have reused this material in all of our workshops and demos for K-12 students.

- Medtronic: has been especially supportive of PRPI and the development of our program, and has invited us to tour their facilities with our students. Medtronic engineers also participated in the symposium we organized as part of the IYL celebration week and in the Information Session for students interested in our academic program.

- "Huracanes y Casa Segura" (Hurricanes and Safe House): we initially participated with them in "INTENOR's Scientific Park Visit" program, and have twice been invited by them to give 30-minute balloon popping demonstrations at Plaza Las Americas, Puerto Rico and the Caribbean's biggest shopping mall.

${ }^{4}$ EDA Project No. 01-01-08278 


\section{DESCRIPTION OF OUR EDUCATIONAL OUTREACH PROGRAM}

With the support of the SPIE Education Outreach Grant and the OP-TEC Student Recruitment Grant we developed in 2014 and 2014 a set of 22 demos and a series of PowerPoint presentations. These have allowed us to do 20-minute to 3hour presentations for different populations. We also developed full-day and two-day long presentations which usually involve a 3-hour workshop where participants build their own telescope using the 2009 International Year of Astronomy Galileoscope kit. We are indebted to Prof. Robert Sparks who shared with us the presentation he developed on how to assemble the Galileoscope. We have added to this presentation optical simulations using OpticStudio from Zemax in order to show our audience how the optics work and the advantages of having the different doublet lens configurations and Barlow lens.

\subsection{Activities for K-12 students}

Both demonstrations and hands-on experiments have been developed for K-12 students. Depending on the type of presentation, size of the group, and available time, we do a different combination of these with or without an accompanying visual (PowerPoint) presentation. We can divide these activities into:

- Laboratory Tours and Open House events: in 2014 and 2015 we partnered with the INTENOR Science Park where our facilities are located, the Arecibo Observatory, and with the Planeta Digital (Digital Planet) Geodome theater to offer schools guided tours that include visits to our labs, and where we provide students with 30-minute optics demonstrations, including balloon popping with lasers. Through this program we impacted over 2,600 students from 36 different elementary, middle, and high-schools. We have also offered 3hour workshops for students in the home-schooling program (71 students and parents) and from the Gifted Children Institute of PR (78 students and accompanying adults). We have had 5 to 16-year-olds participate in these workshops. Students were divided into three groups according to age/grade and every hour the groups changed rooms. Different activities and presentations were setup in each room, and the emphasis and depth of each demo was varied depending on their age.

- Summer Camps: in 2015 we participated in the summer camp organized by the University of Puerto Rico, Rio Piedras Campus (UPR-RP) for K-10 ${ }^{\text {th }}$ grade students. For K- $8^{\text {th }}$ grade students (Campamento Gallitos y Jerezanas), we organized one-hour workshops that we offered at UPR-RP campus (different groups rotated through our classroom during the day for 4 days), for a total of 225 students. $9^{\text {th }}$ and $10^{\text {th }}$ graders had their own "Extreme Summer Camp" and visited our labs where we gave them a 2-hour presentation (25 students). In 2016 we participated in a Summer Camp organized by EngiWorks by giving a 2-hour demo to 33 High-School students. For 2017 we are planning on offering our own 3-week Summer Camp for 25 students (grades 9-10)

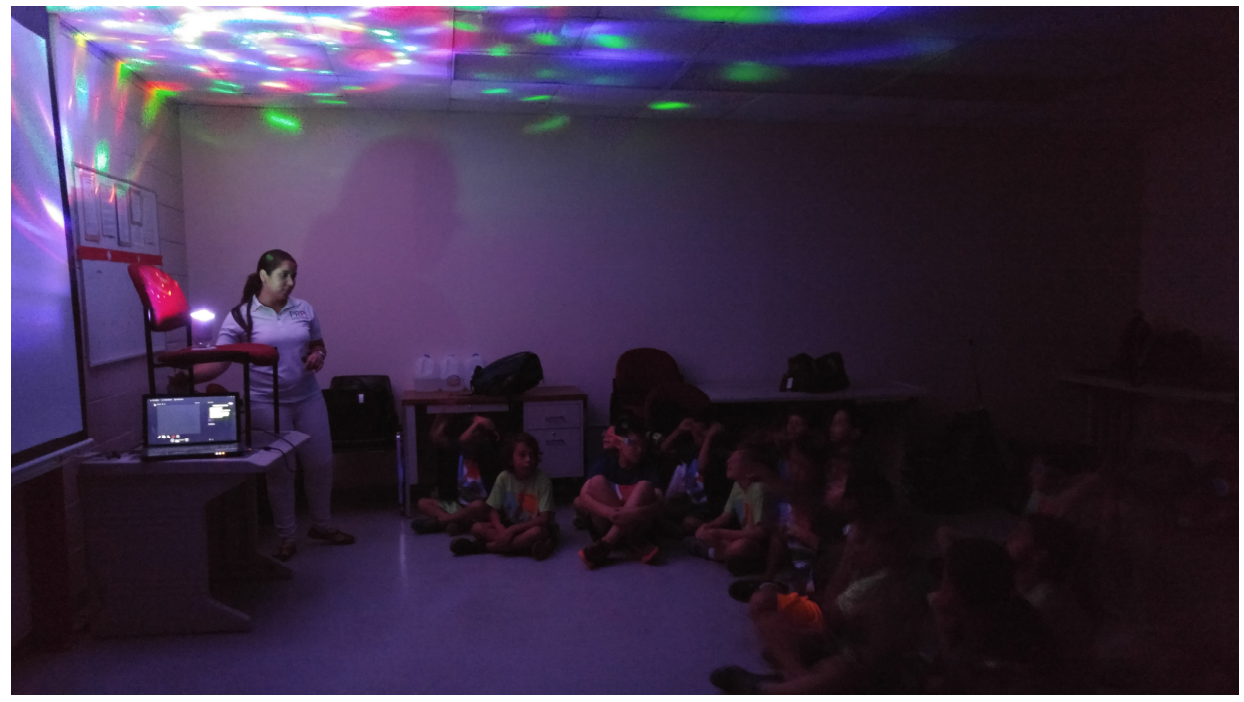

Figure 1. Light presentation at the University of Puerto Rico Summer Camp (Rio Piedras Campus) for K-8th grades. Picture shows elementary students watching Tania Ortiz from the Puerto Rico Photonics Institute. (June 11th, 2015) 
- School visits: we have also visited 12 schools (236 students, mostly $10-12^{\text {th }}$ grades) where we have given 1hour presentations of O\&P and our academic program.

- Other outreach activities: we have also been invited to present at other events that specifically target the K-12 population. These include:

- UMET Science Fair (October 2014 and 2015): where we have had two tables with demos for visiting High School students ( 400 students in 2014 and $~ 700$ students in 2015). In 2015 we also did a 15minute balloon popping presentation in the university auditorium (every hour a different group of students came in).

- STEM's Up to the Challenge (March 2015 and 2016): multiday event held at the Puerto Rico Convention Center, with an estimate of 1,400 students attending in 2014 and 2015.

- Earth Day table with demos at Ft. Buchanan (April 2014, 2015, and 2016): since 2014 we have been participating in this event, attended by students from the Antilles K-12 School System at Ft. Buchanan. We estimate around 300 students have attended each year.

- Manufacturing week event in 2015 (Sept. 2015): we partnered with PRIMEX (The Puerto Rico Manufacturing Extension) to offer 1.5-hour demo sessions to 390 students from Vocational High Schools (students were divided into four groups, each group approximately 100 students)

- Career Day at the Puerto Rico Museum of Art (PRMoA), Sept. 2015: we partnered with the educational division of the PRMoA to have a table and give a 15-minute presentation to almost 400 students attending this event.

\subsection{Workshops for K-12 in-service teachers}

We have partnered with several federal and state programs in order to reach K-12 teachers. The first of these is the Mathematics and Science Partnership (MSP) Program in Puerto Rico. Through this program we gave three workshops in 2014 and 2015 to $600+$ teachers (mostly mathematics and science from middle- and high-school). The first was a daylong workshop, and the other two were three-day (weekend) workshops where we were invited as presenters and plenary speakers.

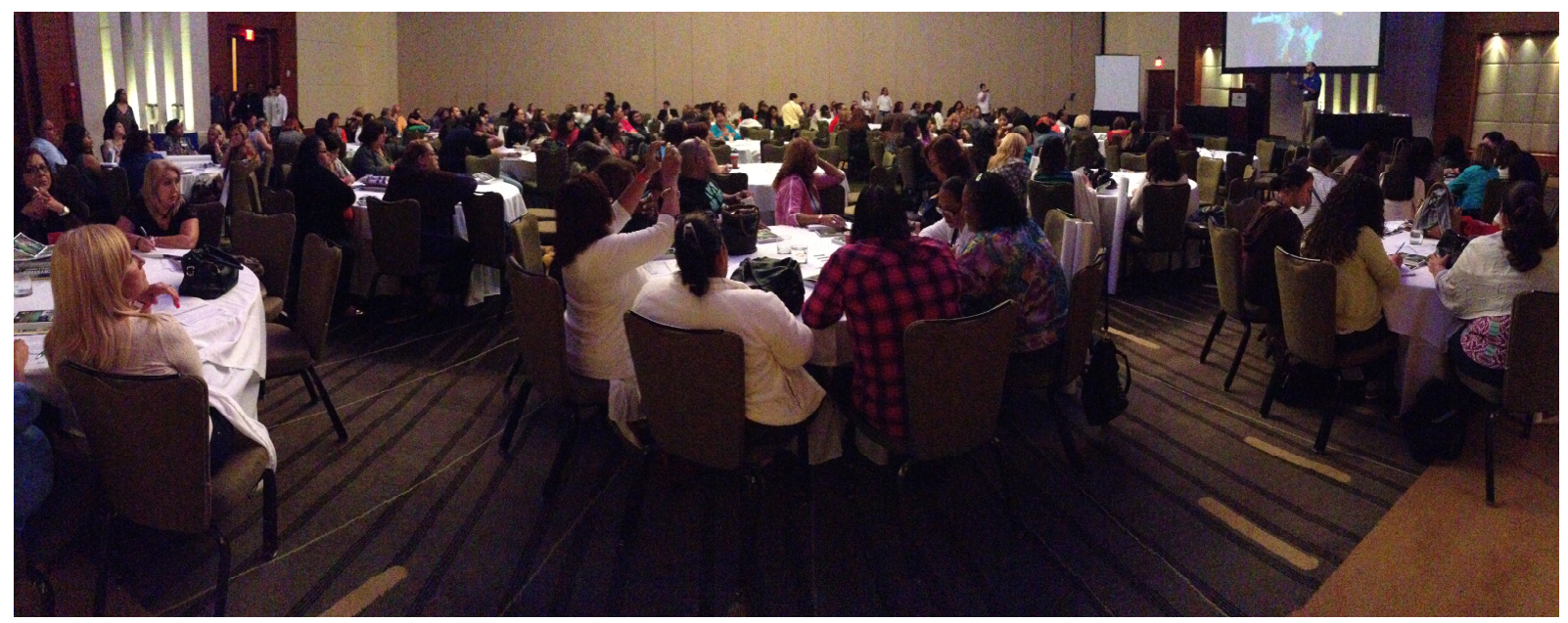

Figure 2. A view of the PRPI Teachers Workshop at the Puerto Rico Math-Science Partnerships Congress, 22 November 2014, in Fajardo, PR.

In 2015 and 2016 we partnered with two state-funded initiatives developed by the School of Environmental Affairs at UMET. The first was the CMECT program (Teacher Competences for Education in Earth Sciences) with 20 participants 
and the second the TICI (Curricular Integration through Research in Environmental Topics) with 17 participants. Both were two-day hands-on workshops, and for the second workshop we managed to give each student a Light Blox kit (from OSA) and a Galileoscope (developed for the International Year of Astronomy 2009). Funds for these projects were provided by the Puerto Rico Council of Education through the No Child Left Behind Law (NCLB-14-15).

\subsection{Outreach activities for the general public}

We have also partnered with other public and private organization to offer events for the general public. Most of the time, these events have also included K-12 and College students. Some of these events are:

- Caribbean Space Summit (Oct. 2014): 150 attendees

- Yuri's Night (during the day), April 2015: partnered with the Visitor Center at the Arecibo Observatory (150 attendees).

- Exhibition at Plaza Las Americas (biggest shopping mall in PR and the Caribbean), Aug. 2015 and 2016: we partnered with "Casa Segura" to give 30 min demos with our balloon-popping setup to provide information about lasers and laser safety, and the principles of color, absorption, reflection, and transmission.

- Space Week at Arecibo Observatory (Oct 2015): 150 attendees at the Arecibo Observatory Visitor Center

- International Educational Congress in San Juan (Feb. 2016): we had a table with demos and information. 100 attendees.

- Job fairs: we have attended more than 10 job fair events in 2015 and 2016 as part of our recruitment campaign. At these events we offer attendees information about our academic program.

\subsection{Video Development}

During 2015, and as part of our outreach commitment for the IYL, we developed two videos explaining the importance of light, optics, and photonics in our daily life and some of its applications. The first video was developed and produced by students from the School of Business and the School of Social Sciences at UMET. As the background for these students was not in science, the production was a process of them learning about the specific phenomenon to be presented and then determining an appropriate way to make that presentation. The second video is a professional production by the environment and science production company Geoambiente, and subsidized by a grant from the PRST and support from UMET. Both videos are in Spanish and available from our YouTube website (search for Puerto Rico Photonics Institute).

\subsection{Research projects with an outreach and educational component}

With the help of undergraduate students, we also had two research projects that we have now integrated to our outreach efforts. The first of these is a web-based educational tool developed by undergraduate students of Computer Science at Universidad Metropolitana. It analytically and graphically studies the behavior of electromagnetic waves as they propagate through space and through an interface between two dielectric media. The animated simulation allows users to manipulate model parameters and acquire an intuitive understanding of how electromagnetic p- and s-waves propagate in a homogeneous medium and are modified as they are refracted and reflected at the material interface. Some interesting particular cases that can be modelled are: normal incidence, critical angle, Brewster angle, and absorptive/amplifying media. We are now working on a second version that incorporates a 3-D view of the waves and shows the behavior in negative-index materials. This program is being used in our Technical Certificate Program in Optics and Photonics and in our undergraduate optics courses, and is available through our website or directly at http://prphotonics.org/software/.

The second is a laser pattern generator that projects Lissajous figures on the ceiling or on a screen. The development was carried out by three undergraduate engineering students, two from the University of Turabo (working in their Capstone Project) and a third from the University of Puerto Rico. We have presented this generator at several of our outreach events with students and teachers. We also had plans to build in association with the PR Museum of Art an improved version that would allow the user to project self-generated art and sketched messages. Unfortunately, the design and safety requirements demanded an investment beyond what we (or the PRMoA) had available at that moment. 


\subsection{Publicity in social and written media, radio, and TV}

Starting in 2014, we developed our own website, Facebook, and Twitter accounts. These have been instrumental in promoting PRPI and the IYL events. For the IYL we also had the opportunity to announce our programs through:

- An interview published by "El Nuevo Día”, the most important newspaper in Puerto Rico

- Several radio interviews

- $\quad$ TV interview at the Sistema TV Network (university and PBS affiliated TV station)

We also developed a 30-second promo that was shown in several movie theatres as part of our recruitment strategy for our academic program.

\subsection{Special populations: Veterans and TAA participants}

We have partnered with the Transition Services Officer of the Soldier for Life-Transition Assistance Program (SFLTAP; Directorate of Human Resources USAG) from Fort Buchanan, the largest military base in Puerto Rico. This partnership started with our participation at the Earth Day events at Ft. Buchanan and has resulted in presentations of our certificate program to veterans transitioning to civilian life (those happened last year, no events of this type have been scheduled this year). We also attended a two-day Hiring Fair for Veterans and their families at Ft. Buchanan on November 4th and 5th, 2015 and another one on June 23rd, 2016.

\subsection{Other IYL activities developed in Puerto Rico}

We would be remiss not to mention many other efforts organized by universities and organizations in Puerto Rico to commemorate the IYL. These include:

- Exhibition "Light: Beyond the Bulb", presented at the José M. Lázaro Library (University of Puerto Rico - Rio Piedras Campus) and at Caribbean University (Bayamón).

- Conference "Stars for All" at the University of Puerto Rico (Rio Piedras Campus) aimed at the blind and visually impaired community of Puerto Rico, presented by Drs. Gloria Isidro and Carmen Pantoja (https://youtu.be/IN9bjCGRukE).

- Podcast "Light Pollution in Puerto Rico" by Mirada Científica, Ciencia PR (in Spanish). Interview with Mr. José Alicea (from the PR Environmental Quality Board) and other experts about light pollution in Puerto Rico (http://www.cienciapr.org/es/podcasts/mirada-cientifica/contaminacion-luminica ).

- Photo Exhibition "Light in Nature" held at the Jobos National Estuarine Research Reserve and organized by the Puerto Rico Department of Natural and Environmental Resources. Held at Cayey, PR.

- Conference on the "Impact of Light Pollution in our Ecosystems" describing the impact of light pollution in astronomy and biology, with examples and summary of laws and regulations. Held at Cayey, PR.

- Second Forum on "Prevention and Control of Light Pollution in Puerto Rico" held in San Juan and organized by Puerto Rico's Board of Environmental Quality.

\section{IYL WEEK IN PUERTO RICO}

The highlight of the IYL 2015 celebration in Puerto Rico was a three-day event hosted by PRPI that included continuing education and scientific conferences (November $5^{\text {th }}, 2015$ ); an open house of the first dedicated photonics laboratory in Puerto Rico and the presentation of the first Technical Certificate in Photonics and Lasers (November $6^{\text {th }}$ ); and a concert that merged the music performed by the Puerto Rico Symphony Orchestra with the science photography and commentary by renowned Puerto Rican astronomer and science communicator, Dr. Jose Francisco Salgado (November $\left.7^{\text {th }}\right)$.

\subsection{Workshop and Symposium}

With the support of the Puerto Rico Science, Research and Technology Trust, PRPI organized a workshop, followed by a symposium on November 5th, 2015 at the main campus of Universidad Metropolitana in Cupey, PR (Muñiz Souffront Auditorium). The morning workshop, entitled "Discovering Light and Exploring Optics through the Galileoscope", 
introduced participants to the basic concepts of optics and photonics through the use of the Optical Society of America's (OSA) Optics Suitcase and LightBlox kits and the 2009 International Year of Astronomy Galileoscope. Each participant built his or her own Galileoscope telescope while learning along the way concepts of lens systems, focusing, imaging and image formation. At the end of the workshop, each participant took home one Galileoscope and other material we distributed. This workshop was opened to the general public and we had 37 participants, including high-school and college students and teachers, technicians and professionals, and general public.

In the afternoon we had a symposium titled "Photonics, Medicine, and the Environment" with two keynote presentations: Dr. Heidy Sierra, Research Fellow at the Memorial Sloan-Kettering Cancer Center in Manhattan, New York; and Dr. Bahaa Saleh, Dean of CREOL, the College of Optics and Photonics at the University of Central Florida. In addition, we had two invited speakers from the industry and the academia in Puerto Rico: Roberto Alzaga, Manufacturing R\&D Technologies, from Medtronic, Inc; and Dr. Samuel Hernández, Director of The Center for Chemical Sensors Development of the University of Puerto Rico at Mayagüez.

Four hours of Continuing Education credit were given to the participants who so desired for each session (morning or afternoon).

\subsection{PRPI laboratory inauguration, Open House, and launch of our 1-year certificate}

On the morning of November $6^{\text {th }}, 2015$, we had the official inauguration of our labs and our first Open House, as well as the launch of our first academic program, a one-year certificate in "Photonics and Lasers Technical Specialist", which had been recently approved by the Puerto Rico Council of Education. We had presentations, educational activities and demos, and tours of our labs.

\subsection{Concert of Light by the Puerto Rico Symphony Orchestra}

On the evening of November $7^{\text {th }}, 2015$ the Puerto Rico Symphony Orchestra presented the Concert of Light at the Center for Performing Arts in San Juan (Pablo Casals Symphony Hall). This presentation featured the science photography and commentary by renowned Puerto Rican astronomer and science communicator, Dr. José Francisco Salgado, providing a multimedia experience in an innovative pairing of science and art. The visual representation of Dr. Salgado was accompanied by the orchestral suite The Planets op. 32 by Gustav Holst. The program also had the soloist Benito Díaz interpreting Strauss' second concert for trumpet and orchestra and the piece Borealis by the composer John Estacio, also with the visual representation of Dr. Salgado.

This combination of science and symphony has been presented in more than 100 concerts and has reached a combined audience of more than 250,000 people in concert halls and educational institutions spanning 45 cities in 15 countries. Some of the orchestras that have presented these works include the Chicago Symphony Orchestra, the Boston Pops, the San Francisco Symphony, the Orchestra Teatro Regio Torino and the Chicago Sinfonietta.

\section{REWARDS, RESULTS, AND CHALLENGES}

\subsection{Significance of our outreach program}

Since 2006, Puerto Rico has experienced economic upheavals that have severely impacted the local workforce, with an unemployment level that currently reaches $15 \%$ and a workforce that has fallen by nearly 400,000 . Through our New Horizons initiative, the Puerto Rico Photonics Institute is helping to address this situation by providing training in the new and fast-growing fields of lasers, optics, and photonics; by having participants in our program acquire skills applicable to a wide range of fields where photonics is an enabling technology; and by providing those participants with work experience to prepare them for careers as optics technicians. Furthermore, local state plans are already focused in expanding the industry base to include those related to lasers and photonics. In order to be able to achieve this goal, we have developed a very strong marketing and recruiting campaign allowing us to reach out to:

- students in high schools throughout Puerto Rico who are unaware of optics and photonics as a Career Path.

- displaced workers, particularly TAA-eligible and veterans as well as other adults who may be interested in obtaining stackable and transferable education and training in optics and photonics.

- workers of industries where optics and photonics is an enabling technology. These workers will benefit from our Technical Certificate in Photonics and Lasers. 


\subsection{Results}

To date we have been able to reach an audience of more than 9,500 including almost 3,000 K-12 students that have visited our labs and more than 700 teachers through our workshops. The map below summarizes the locations of the schools that have visited our labs (red), the schools we have visited (yellow), the workshops we have given (dark blue), visits to veterans (green), other outreach events (orange), and the place of origin of the teachers that have attended our workshops (shaded, from almost every municipality in Puerto Rico).

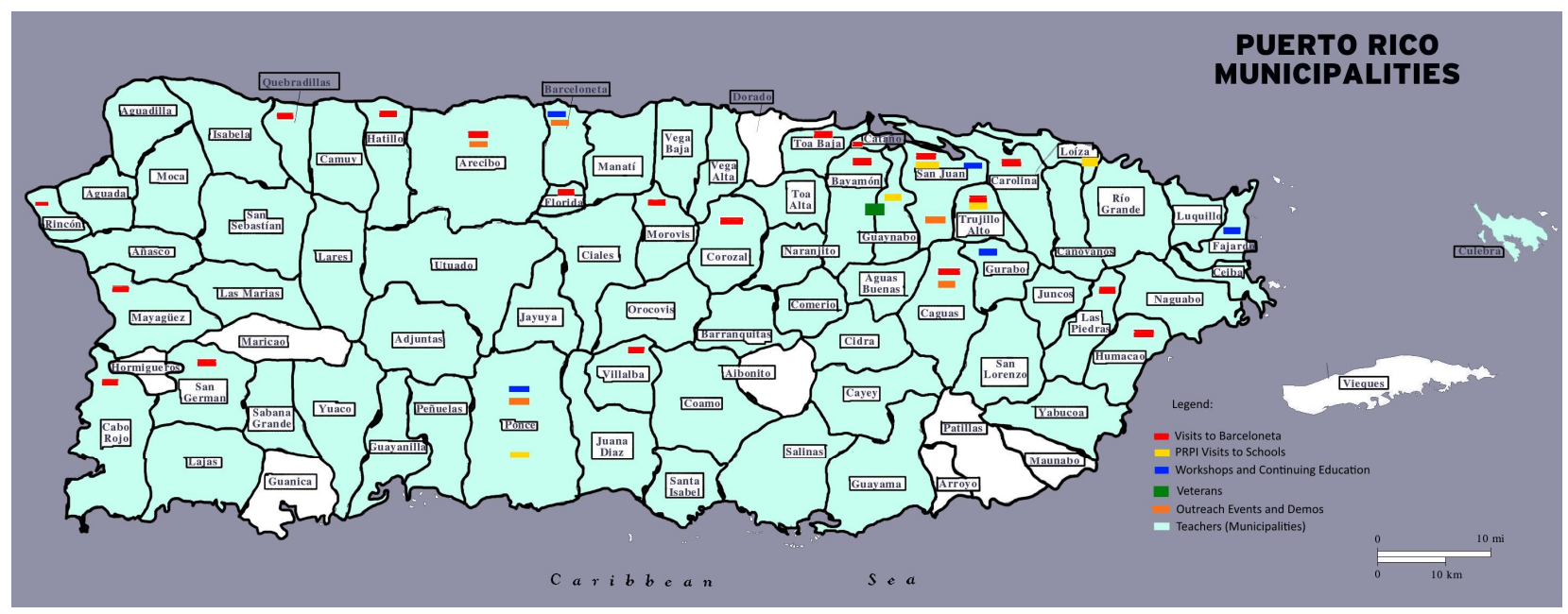

Figure 3. Summary of municipalities impacted by different activities of our outreach program.

\subsection{Challenges}

The Photonics STEM field in Puerto Rico is affected by three main broadening participation (BP) challenges. First, the current economic situation in Puerto Rico prevents many prospective students from pursuing an education since they cannot pay for it (or for what the student aid programs cannot cover) themselves and are unwilling to commit to any student loan. Second, the cultural and language barrier prevents many from even considering applying to graduate school at a university in the continental US. Third, the challenge faced by the photonics industry worldwide that is growing at a faster pace than the number of professionals being trained in the field. Since we started our outreach program in 2014, we have adapted to these particular socio-economic situations by:

- Partnering with local, state, and federal institutions, non-profits, and private companies and organizations to maximize the availability of resources. Many of these resources have been in-kind.

- Combining our academic, research, marketing, and outreach activities in order to better use the available resources.

- Developing an academic program that responds to local and national needs.

- Integrating different types of populations (K-12 students, teachers, TAA participants, and veterans) into our programs.

We are also in the process of learning how to best translate our outreach program into an effective recruiting program that will bring students into our academic programs. On the other hand, the relatively small number of students that have registered in our first and (soon-to-begin) second cohorts have made it more manageable to develop and polish our courses. We look forward to continue developing alliances that will enable us to further our development as a Photonics Institute. 


\section{CONCLUSIONS}

Latinos, and particularly Latina women are traditionally under-represented in STEM fields [1]. The population of Puerto Rico is virtually all Latino and citizens of the United States, but at the same time, there is a very high level of economic hardship, with $45 \%$ of the population living below the poverty line and nearly all young people requiring federal and other financial aid to attend college. Women represent a solid proportion of students, and there is a large community of military veterans. At the same time, Puerto Rico has a solid higher education system and potential for a solid education system at all levels. In this context, the establishment of a Photonics Institute aims at using our local strengths in order to firmly establish in Puerto Rico a community of experts in Optics and Photonics. These areas have been called "key enabling technologies" for the 21st Century and have become "drivers for technological innovation and economic growth" effectively becoming "essential technologies for our nation" $[2,3]$.

The Puerto Rico Photonics Institute comes to Puerto Rico at both a precarious and opportunistic moment for the island. While the economy is in dire straits and the population is falling as people move to greener pastures in the mainland US, new prospects are opening up. PRPI is well-placed to be part of a rebirth of opportunity in Puerto Rico. PRPI is positioning itself through outreach, recruiting, media, and collaborations to be a prominent player in this rebirth. We have responded to these challenges by creating a 1-year Photonics \& Lasers Technical Specialist certificate, developed and supported under a grant from the US Department of Labor. This first step has allowed us to develop a 2-year Associate Degree in Photonics and Lasers Engineering Technology to further our academic and research programs. In this paper, we have presented a summary of the activities that PRPI has undertaken to promote its program, the science and technology of photonics, STEAM education, and career opportunities in Puerto Rico.

\section{ACKNOWLEDGMENTS}

The authors are thankful for the support of the following organizations: the Puerto Rico Industrial Development Company (PRIDCO), the Puerto Rico Science, Technology and Research Trust, the National Center for Optics and Photonics Education (OP-TEC), the US Department of Labor Employment Training Administration, Edmund Optics, the Optical Society of America (OSA), and SPIE.

\section{REFERENCES}

[1] Cole, D. and Espinoza, A, "Examining the Academic Success of Latino Students in Science Technology Engineering and Mathematics (STEM) Majors," J. Coll. Student Dev. 49(4), 285-300 (2008). DOI: 10.1353/csd.0.0018

[2] National Research Council, [Optics and Photonics: Essential Technologies for Our Nation], Washington, DC, The National Academies Press (2012).

[3] NSF, "Dear Colleague Letter: Optics and Photonics (OP)", Arlington, Virginia (2015). www.nsf.gov/pubs/2016/nsf16004/nsf16004.jsp 